A реконструируемый фрагмент синоптической части СЯД, на основе предложенной И.В. Ружицкого, может быть представлен следующим образом:

(Б) ЖИЗНЬ $\leftrightarrow$ ВРЕМЯ<...>

Б.V. [начало - конец] заглохнуть, закончиться, начаться, покончить; окончательный, пожар, последний, прежний, твёрдый; полно, окончательно, твёрдо; начало, источник, конец, край, точка, черта

(В) ВРЕМЯ $\leftrightarrow$ СМЕРТЬ $<\ldots>$

B.II.1. умереть (умирать), погибать (погибнуть); кровавый, мёртвый, смертный; бытие, гроб, могила, погибель, пожар, смерть, сон

B.II.2. губить (погубить); война, гибель, дуэль, катастрофа

В заключение отметим, что предлагаемый авторами СЯД способ конструирования тезауруса Достоевского не является, безусловно, единственно возможным, однако основывается он на объективном многопараметровом лексикографическом анализе всего корпуса текстов писателя: с учётом ближних и дальних синтагматических связей, паратаксиса, ассоциативного окружения и когнитивного потенциала.

Публикачия подготовлена в рамках поддержанных РФФИ научных проектов (грант № 15-04-00135).

$* * *$

1. Достоевский Ф.М. Полное собрание сочинений: в 30 т. - Л.: Наука, 1972-1990.

2. Караулов Ю.Н., РужицкийИ.В. От словаря языка писателя к познанию его мира: о некоторых базовых концептах в творчестве Ф.М. Достоевского // Вопросы когнитивной лингвистики. -2015. - № 4 (045). - С. 16-22.

3. РужицкийИ.В. Язык Достоевского: идиоглоссарий, тезаурус, эйдос: Монография. - М.: ЛЕКСРУС, 2015. $-543 \mathrm{c}$.

4. Русский семантический словарь. Толковый словарь, систематизированный по классам слов и значений / РАН. Ин-т рус.яз. Под общ.ред. Н.Ю. Шведовой. Т. 3. - М.: Азбуковник, 2003. - 720 с.

5. СЯД 2008 - Словарь языка Достоевского: Идиоглоссарий (А-В) / Под ред. Ю.Н. Караулова. - М.: Азбуковник, 2008.

6. СЯД 2001 - Словарь языка Достоевского: лексический строй идиолекта / Под ред. Ю.Н. Караулова. - М.: Азбуковник, 2001. - Вып. І. - 442 с.

7. ТопоровВ.Н.Миф. Ритуал. Символ. Образ: Исследования в области мифопоэтического: Избранное. - М.: Прогресс-Культура, 1995. - 624 с.

8. Чернова Н.В. «Господин Прохарчин»: Символика огня // Достоевский: Материалы и исследования. Т. 13. - СПб.: Наука, 1996. С. 29-49.

\title{
Шокиров Ш.И. \\ Вопросы перевода с одного языка на другой лексем с семантикой «кўз» (глаз) в английском и узбекском языках
}

Андижанский государственный университет

(Узбекистан)

doi: $10.18411 / s p c-26-12-2017-05$

idsp: 000001:spc-26-12-2017-05

\section{Аннотация}

В статье освещаются структурные и семантические свойства конституентов лексико-семантического поля «Глаз(а)» английскогои узбекского языков.

Ключевые слова: лексико-семантическое поле, лексема,номинатив, коннотатив, ядро, периферия, план выражения,тематические группы. 


\section{Abstract}

The article deals with the structural and semantic features of the conctituent lexemes of the lexical-semantic fields of "eye" in modern Englishand Uzbek.

Key words: lexical-semantic field,lexeme,nominative connotative, centre, periphery, surface structure,thematic groups.

Сегодня, когда широко распространяются процессы глобализации, сильно растет потребность в деятельности практического перевода. Перевод и переводческая деятельность устанавливает сотрудничество между народами и усиливает задачу «моста» развития. И именно поэтому возросла необходимость улучшения качества переводимых произведений (текстов), потребность многоязычным словарям.

Основная цель практического перевода - передача смысла, значения и коммуникативной цели, выраженными иноязычными словами, на языке перевода. В этом процессе единицы перевода (транслатемы) [4., с. 194-196] считаются второстепенными. Одной из актуальных проблем современного перевода является не только подготовка кадров по художественному и нехудожественному переводу, но и требованияучитывать стилевые, функциональные, асимметрические и семантические свойства лексических единств в процессе перевода, то есть наряду с такими видами лексических единиц, как прямое, переносное, непроизводное, производное, свободное, несвободное, номинативное и коннотативное, [2., с.50-51] изучение их психологических, региональных, исторических, географических и других свойств имеет немаловажное значениев решении поставленной задачи.

В этом смысле, при переводе конститутиентов лексико-семантического поля слова «глаз» («кўз»)с английского языка на узбекский существует ряд факторов, препятствующие полному и точному переводу. Они препятствуют полному и точному переводу. Когда говорим лексико-семантическое поле, то имеем в виду сложные лексические микротизмы. Эти микротизмы имеют свойственную им структуру, объединяет слова по смыслу. Одним из характерных свойств является место понятия центра и периферии, а также поле в виде иерархии, а именно размещение в виде ступеней. Субстантивы, имеющие эти малые семы в выражении семантического поля семы глаз; в основном это зрачок, ресницы, веки брови, глазное яблоко и находит в них свое выражение. Такие семы заметны в глаголах типа -кўрмоқ - видеть, қарамоқ смотреть, кўзламоқ - высматривать, тикилмоқ -пристально смотреть, кўз тутмоқ приглядеть, кўз уруштирмоқ - просмотреть, кўз юммоқ - закрыть глаза, кўзини олиб қочмоқ - прятать глаза, а также в сложных существительных узбекского языка кўк -кўз (синеглазый), турт-кўз (о человеке, который носит очки). Микрополя образующие конститутиенты лексемы «глаза», можно изобразить в структуре: 1-схема

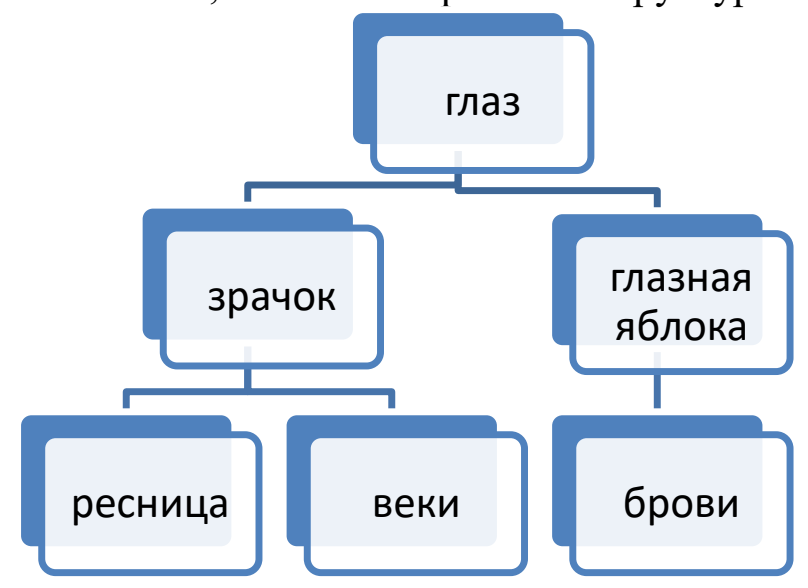


Семантическое поле - с лексического аспекта имеют общую сему и отражают объективную реальность соответствует самым большим лексико-семантическим парадигмам группам различных слов. Функционально- семантическое поле - средства, принадлежащие к различным пластам языка (морфологические, синтаксические, средства словообразования, лексические), а также, это система общего характера, объединенного с

Семантическое поле объединяет вокруг своего центра (ядра), выявляющего значение, слова с обобщенным значением. В центре исследования значения слова и слова вбирающего в свое поле связаны друг с другом. Здесь обобщено семантическое поле и схожи словообразовательными средствами, но может включать схожи.

2-схема

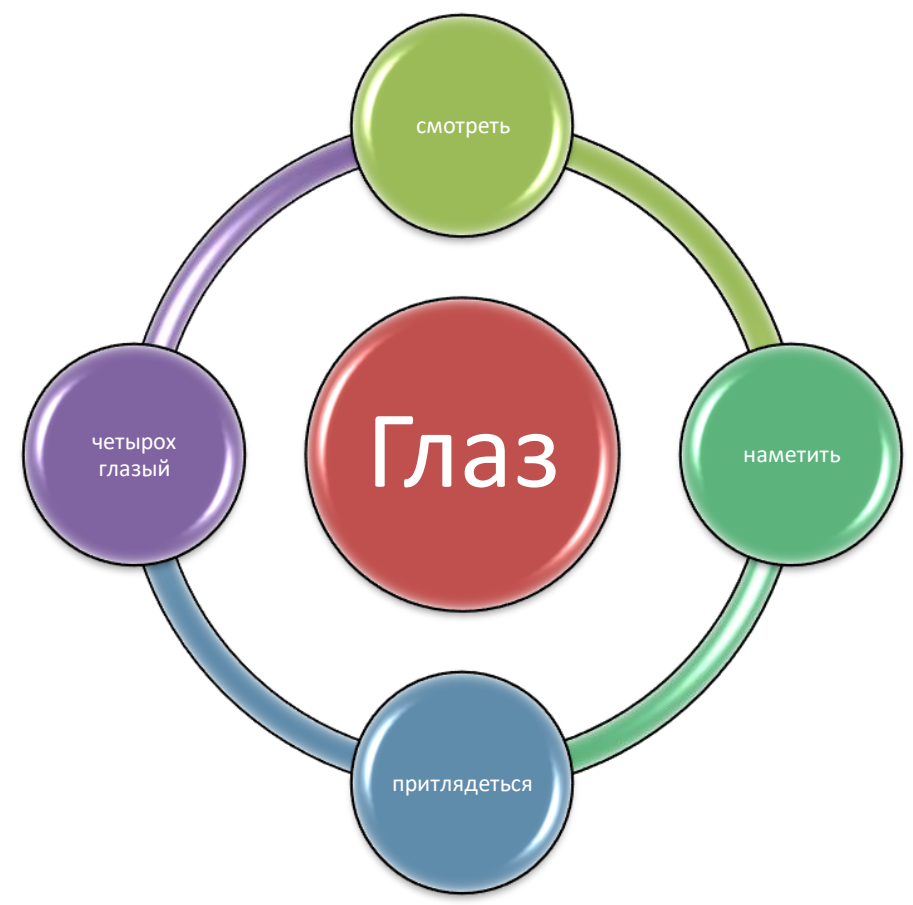

Обычно как основной элемент поля выступают однозначные слова, а в некоторых случаях лексико-семантические варианты многозначных слов. В зависимости от выражаемого значения (семы), лексико-семантическое поле может включать в себе слова одной или нескольких частей речи. Например, «Глаз» (сущ.субстанция), «кўрмоқ» (смотреть) - отглагольное существительное, «кўрмоқ, кўзламоқ» (видеть, присмотреть) - глагол, «кўз остига олмоқ», «назарташламоқ» (предусмотреть, бросить взгляд) - фразеологические единства, «қора кўзлар», «кўк кўз», 〈ғилай кўз» (черные глаза, синие глаза, косые глаза)-определение, как и глагол «кўрмоқ» (видеть) в морфологическом отношении не привязывается к субстантиву, то в семантическом отношении они требуют постановки друг друга. [6., с.531-554 ]

Исследование генетически не связанных языков учёные-языковеды проводят с помощью инструментального и логического аппарата когнитивной лингвистики. Сюда можно отнести понятие «концепт».

Лексема - связь между словом и понятием, т. е. сигникативнаясвязь, смысл, выраженный в результате этой связи называется концептуальным смыслом и это понятие, являясь логической категорией, имеет важное значение в рациональном познании окружающего мира. [2., с.65-69]

Лексико-семантическое поле (ЛСП) и Лексико-семантическая группа(ЛСГ) не принадлежат к одной семантической системе. Лексико-семантическое полев отличии от 
лексико-семантической группы не имеет компонентов, отличающихся разными видами связи друг с другом.

Раскрытие сущности лексемы предполагает изучение изменения её семантики, исследование отношения с другими лексемами, анализ и классификация структуры лексического значения, выявление их синтагматики,т.е., возможности сочетания с другими лексемами. К ним можно отнести следующее:

1. Полисемантичность и полифункциональность слова «кўз» (глаз);

2. существование синонимических, омонимических и антонимических отношений между членами парадигмы поля, без учёта особенностей их уровня значения;

3. широкое или ограниченное применения слов с семантикой слова«кўз» с исторической и географической точек зрения;

4. несуществование на языке перевода соответствующих в оригинале эквивалентов языковых единиц;

5. не учитывать в процессе перевода национальных, речевых, жизненных ситуаций и другие особенности.

В «Толковом словаре узбекского языка» и третьем новом международном словаре Вебстера (1993) слову глаз дается толкование на узбекском «тирикмавжудотнингкўриш аъзоси», на английском «the organ of sight» (орган зрения живых существ). Его другие значения - взгляд, взор, способность видеть и смотретьв английском языке имеют соответствующие эквиваленты: look, glance, gaze, sight, vision.

Слово “кўз” в отдельности, в словосочетаниях, в составе фразеологических сочетаний выражает прямое и переносное значение во всех трёх языках. Анализы показывают, что при переводе часть их имеют соответствующие эквиваленты, ау некоторых они отсутствуют.

Например, eyeball - кўз соқаси, глазное яблоко, eyebrow- қош, бровь, eyedropкўзга томизадиган дори, капли для глаз, eyeful-ажойиб манзара, удивительная картина, очень красивая женщина, eyeless- кўзи кўр, без глаз, слепой, eyeopener- хайратланарли кўз, новость, очень удивившая человека, eye- tooth- сўйлоқ тиш, молочные зубы, to wink, to blink- кўз қисмоқ, учирмоқ, подмигнуть, моргать, iris- кўз гавхари, радужная оболочка.

Есть и словосочетания со словом «кўз» (глаз), большинство из которых переводится на сопоставляемых языках соответствующими словосочетаниями:to run/cast one's eye sover smth-бирор нарсани тез оқиб, кўз югуртирип чикмоқ, (просмотреть быстро читая что-то), to give an eye to- кўз - қулоқ бўлиб турмоқ, ғамхорлик қилмоқ, эътибор бермоқ (быть внимательным, проявлять заботу, обращать внимание); to have an eye on smth-бир кўзи бирон нима болмоқ (одним глазом смотреть на что-то); in front of (before) sb's (very) еуе-кимнидир кўз олдида (перед чьим-то глазами); to open (to close) one's eyes кўзини очмоқ (юммоқ) (открыть (закрыть) глаза). Как видно из примеров, словосочетания со словами «кўз» (глаз) при переводе на узбекский язык могут иметь несколько вариантов. Однако словосочетание to open sb's eyes - в определённой речевой ситуации могут обозначать быть внимательным совершение неверных поступков. Например, open your eyes boys ! The examination term is at hand - кўзларингни очинглар, болалар! Имтихон даври яқинлашиб қолди! Откройте глаза, дети! Приближается время экзаменов!

Словосочетание in the public еуе дословно переводится как халқ (одамлар) орасида тез-тез кўринмоқ (часто появляться на глазах людей). Однако будет точнее перевести быть на виду улюдей (народа), быть известным, знаменитым. Есть и такие словосочетания, дословный перевод которых передаёт неверный смысл предложения. 
Например, a black eye/to black sb's eye - қора кўз (кимнидир кўзини қорайтириб) деб эмас (чёрные глаза, а не чернить чью-то глаза) ё кўкарган кўз (кимнидир кўзини кўкартирмоқ) (мушт билан зарба бериб) следует понимать в значении синяк от удара под глазом.

Сложное слово еуе-opener является существительным и имеет полисемантические свойства. Его первое значение действительное удивление (her confusion was a real eye-opener), второе - ликёр или спиртные напитки, принимаемые с утра (one eye opener), третье - ежедневнопервая принимаемая наркотическаяинъекция для лечения (Now it was so bad that she was up before down for an eye - opener). Нужно принять во внимание, что это выражение свойственно разговорному стилю английского языка.

Переводчик, не знающий значение многозначного слова в конкретной ситуации, в процессе перевода может допустить грубые ошибки. Например, сложное слово еуеproper, имеющее в своём составе proper-означает- "шиқ-шиқ тугма" “ пистон” «пуговица», «кнопка». В сочетании со словомеуе оно даёт значение: 1. Удивительный предмет(хайратга солмоқ) (what an eye properstory); 2. Красивая, прекрасная изящная, статная женщина (девушка)( чиройли, кўркам, гўзал, зебо) (Is not that foxy lady an eyeopener?).

Или сочетание «еуе ball to eye ball», передовая значение лицом к лицу (face to face), при дословном переводе предстает как (кўз соққаси) «глазное яблоко». Поэтому предложение they approached each other eyeball to eyeball and frowned целесообразно переводить как: Они встали лицом к лицу и нахмурились (улар юзма-юз яқинлашдилар ва қовоқ солдилар).

Свойственные к разговорному стилю выражения «Mind your eye», «Take care! Look out» (Қара, Эхтиёт бўл, кўзинга қара) Смотри, Будь осторожен, предупреждения, имеют значение быть внимательным. Сложное прилагательное«Blue-eyed» (голубо глазый- кўк кўзли) в зависимости от ситуации в разговорной речи переводится в двух вариантах: Blue-eyed man - кўк кўзли киши (голубоглазый человек) и Blue-eyed boy эркатой, арзанда. (баловень, любимчик). Как видно из примеров при присоединении «blue eyed» к слову «bоy» в конкретной разговорной ситуации приобретает второе значение.

A blue-eyed boy carried my luggage to my place.

Голубоглазый мальчик (мальчишка) отнес мой груз ко мне домой.

Кўк кўзли бола(кай) юкимни уйимга олиб келди.

$\mathrm{He}$ is the only son of his parents. He does not do anything at home. A blue eyed boy!

Он любимчик родителей и дома ничего не делает.

У ота-онасини арзандаси. У уйда хач нарса қилмайди.

Если сочетание слов «То catch someone's еуе», свойственно неофициальной речии выражает значение привлечения внимания к себе, то выражение to see eye to eyeприсоединяться к чьему-либо мнению( кимнидир фикрига тўла кўшилмоқ). (She and I see eye to eye on this matter). Словосочетание спредлогом «Up to the eyes in (work etc.) выражает значение«бытьзанятымкаким-либоделом», «окунутьсявработу» “бир иш билан жуда бант бўлмоқ” “ишга қўмилмоқ” “бош қашигани вақти бўлмайдиган”! the farmers are up to the ayes in harvesting.

Сочетание «То keep an eye on», свойственно художественному стилю и имеет определенную выразительность. На узбекский язык оно переводится как «кўз-кулоқ бўлиб турмоқ, назорат қилиб турмоқ» (быть бдительным, контролировать). 
В процессе анализа выяснено, что сложное слово на узбекском языке «кўзмунчоқ» переводится на английский посредством описани я как «a black bead with a white dot attached to protect children from the evil eye», «an evil eye killing beads».

Если сочетание «The naked еуе» на узбекский язык переводится не как «ялонғоч кўз» (голые глаза), а как «невооруженный глаз» (қуролланмаган кўз), (только глазами человека без каких- либо приспособлений), то следуетучесть, что «an eye for an eye» (a tooth for a tooth) переводитсякак «қонга-қон, жонга-жон» (кровь за кровь, жизнь за жизнь).

При определении значения лексических единиц со словом «кўз» (глаз) важную роль играют слова, сочетающиеся с данным словом. Например, «кўз юммоқ» всочетании со словом «дунёдан» означает «қазо қилмоқ» (скончаться), «ўлмоқ» (умереть) и переводится на английский язык как «to die», «to be no more», «to join the majority», «кўз ёрмоқ» - to give a birth, «to bear baby». Все вышеперечисленные лексемы свойственны разговорной речи.

Когда речь идет о стилистике перевода, то надо подчеркнуть, что переводчик должен знать, что «кўз духтири (глазной доктор) относится к разговорному стилю, «кўз шифокори» (глазной врач) - к художественному, а «офтальмолог» и «окулист» к научному.

В заключении хочется отметить, что выводы, сделанные в ходе анализа перевода узбекского слова «кўз» на английский язык,послужат улучшению качества перевода и внесут определенную ясность вопросам теориитранслатологии.

$$
\text { *** }
$$

1. Толковый словарь узбекского языка Т. 1-5. Ташкент, «Нац.энциклопедия Узбекистана», Государственное научное издательство, 2006, с.156-157.

2. Собиров А. Исследование на основе направления системы лексического уровня узбекского языка.Т.: Маънавият, 2004, c.69.

3. БутаевШ. English-Uzbek, Uzbek-English Dictionary, «o'qituvchi NMIU, Tashkent 2003, c. 83-84.

4. Webster's third New International Dictionary. Копетапп, 1993, c. 416-417.

5. ХошимовТ.M. Simultanous translation and factor of source language: in actual problems of modern translatology,Андижан, 2008, с. 416-417.

6. Вендлер 3. О слове good// Новое в зарубежной лингвистике. Вып. Х. Лингвистическая семантика М. 1982, c. 531-554. 